\title{
Repercussões da pandemia da COVID-19 em mães- crianças com síndrome congênita do Zika
}

Repercussions of the COVID-19 pandemic in children and mothers with Congenital Zika Syndrome Repercusiones de la pandemia de COVID-19 en madres-niños con síndrome congénito del Zika

Paulo Roberto Lima Falcão do Vale ${ }^{1,2}$ is https://orcid.org/0000-0002-1158-5628

Evelyn Siqueira da Silva ${ }^{1}$ id https://orcid.org/0000-0003-4367-9263

Jessica Santos Passos Costa² id https://orcid.org/0000-0001-8557-5783

Rosely Cabral de Carvalho² io https://orcid.org/0000-0002-1060-2780

Evanilda Souza de Santana Carvalho ${ }^{2}$ id https://orcid.org/0000-0003-4564-0768

Como citar:

Vale PR, Silva ES, Costa JS, Carvalho RC, Carvalho ES. Repercussões da pandemia da COVID-19 em mães-crianças com síndrome congênita do Zika. Acta Paul Enferm. 2021;34:APE03123.

DOI

http://dx.doi.org/10.37689/actaape/2021A003123

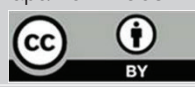

Descritores

COVID-19; Crianças com deficiência; Cuidado da criança; Infecções por coronavirus; Pandemias;

Relações mãe-filho; Zika vírus

Keywords

COVID-19; Child car; Coronavirus infections; Disabled children; Mother-child relations; Pandemics; Zika virus

Descriptores

COVID-19; Cuidado del niño; Infecciones por coronavirus; Niños con discapacidad; Pandemias; Relaciones madre-hijo; Virus zika

Submetido 2 de Fevereiro de 2021

Aceito

23 de Março de 2021

Autor correspondente

Paulo Roberto Lima Falcão do Vale

E-mail: paulofalcaovale@ufrb.edu.br

\section{Resumo}

Objetivo: Analisar as repercussões da pandemia da COVID-19 em mães-crianças com síndrome congênita do vírus Zika.

Métodos: Estudo misto sequencial exploratório (QUAL->QUAN), realizado com 44 mães de crianças com SCZ respondentes de questionário online aplicado entre abril e maio de 2020. Os dados qualitativos foram submetidos à análise de conteúdo temática e os quantitativos à estatística descritiva, com aplicação do teste $t$ de Student emparelhado. A integração dos dados foi realizada de acordo com a técnica joint display.

Resultados: 0 distanciamento físico reconfigura a rotina da mãe-criança, limita a desenvolver atividades no ambiente doméstico, altera hábitos, aumenta a sobrecarga da cuidadora $(p<0,05)$, implica em alteração do padrão do sono e gera sinais de estresse e ansiedade. As mães se preocupam com a diminuição da renda familiar e se esforçam para realizar exercícios de estimulação e atividades escolares no ambiente doméstico após a interrupção dos cuidados profissionais de reabilitação e o fechamento das escolas.

Conclusão: A pandemia da COVID-19 repercutiu no incremento de novas tarefas de cuidado com a criança e ambiente doméstico, bem como elevou os níveis de sobrecarga de cuidado das mães, o que pode resultar em alterações importantes na saúde física e mental delas.

\section{Abstract}

Objective: To analyze the repercussions of the COVID-19 pandemic in mothers-children with Congenital Zika Syndrome.

Methods: This is a mixed exploratory sequential study (QUAL-> QUAN), carried out with 44 mothers of children with Congenital Zika Syndrome who answered an online questionnaire applied between April and May 2020. Qualitative data were subjected to thematic content analysis and quantitative data to statistics descriptive, with application of paired Student's t test. Data integration was performed according to the joint display technique.

Results: Physical distancing reconfigures the mother-child routine, limits the development of activities in the domestic environment, changes habits, increases caregivers' burden $(p<0.05)$, implies changes in sleep patterns and generates signs of stress and anxiety. Mothers are concerned about the decrease in family income and strive to perform stimulation exercises and school activities in the domestic environment after the interruption of professional rehabilitation care and the closing of schools.

Conclusion: The COVID-19 pandemic had an impact on the increase in new tasks of caring for the child and the home environment, as well as raising the levels of care burden for mothers, which can result in important changes in their physical and mental health. 


\section{Resumen}

Objetivo: Analizar las repercusiones de la pandemia de COVID-19 en madres-niños con síndrome congénito del virus del Zika.

Métodos: Estudio mixto secuencial exploratorio (CUAL->CUAN), realizado con 44 madres de niños con SCZ que respondieron un cuestionario digital aplicado entre abril y mayo de 2020. Los datos cualitativos fueron sometidos al análisis de contenido temático y los cuantitativos a la estadística descriptiva, con aplicación del test-T de Student pareado. La integración de los datos se realizó de acuerdo con la técnica joint display.

Resultados: El distanciamiento físico reconfigura la rutina de la madre-niño, limita el desarrollo de actividades en el ambiente doméstico, altera hábitos, aumenta la sobrecarga de la cuidadora ( $p>0,05)$, implica la alteración del patrón de sueño y genera señales de estrés y ansiedad. Las madres se preocupan por la reducción de los ingresos familiares y se esfuerzan para realizar ejercicios de estimulación y actividades escolares en el ambiente doméstico luego de la interrupción de los cuidados profesionales de rehabilitación y del cierre de escuelas.

Conclusión: La pandemia de COVID-19 repercutió en el aumento de nuevas tareas de cuidado del niño en ambiente doméstico, así como también elevó los niveles de sobrecarga de cuidado de las madres, lo que puede dar como resultado alteraciones importantes de su salud física y mental.

\section{Introdução}

A notícia que o mundo convivia com a pandemia da COVID-19 foi emitida pouco mais de quatro anos após a epidemia global do vírus Zika e suas consequências como Síndrome Congênita do vírus Zika (SCZ). Até 30 de setembro de 2020 o Brasil respondia por $28 \%$ dos casos confirmados e $55 \%$ dos óbitos por COVID-19 na região das Américas, ${ }^{(1)} \mathrm{com}$ taxa de letalidade de 3,0\%. ${ }^{(2)} \mathrm{O}$ Brasil também se destaca como o país com maior prevalência da SCZ, mantendo a ocorrência de casos até os dias atuais, totalizando 3.534 crianças com SCZ desde 2015, dentre os quais, 13 foram confirmados de janeiro a maio de 2020. ${ }^{(3)}$

As medidas sanitárias de controle da transmissão do vírus da COVID-19, provocaram impactos negativos na saúde mental da população, ${ }^{(4)}$ assim como a descoberta da SCZ gerou sentimentos e emoçôes desagradáveis para as mães. ${ }^{(5)} \mathrm{A}$ definição de SCZ engloba o conjunto de alterações neurológicas causadas pelo vírus Zika através de transmissão congênita, causando desproporção craniofacial e outras anomalias cerebrais. ${ }^{(6)}$

Mãe e criança constroem, sustentam e compartilham de uma relação intimista regulada por aspectos biológico, social e psicológico cultivados em prol do desenvolvimento da criança, ${ }^{(7)}$ por isso esse estudo adota o termo díade máe-criança com SCZ.

As crianças dependem total e quase exclusivamente das mães, ${ }^{(8)}$ utilizam medicamentos diariamente a fim de amenizar os episódios de espasmos, rigidez muscular e, principalmente, convulsóes. ${ }^{(9)}$ Por sua vez as mães percorrem itinerários terapêuticos desgastantes em prol do desenvolvimento in- fantil, ${ }^{(5)}$ convivem com níveis elevados de depressão e ansiedade, além de diminuição na qualidade de vida no primeiro ano de vida da criança. ${ }^{(9)}$ Elas vivenciam uma rotina cansativa, com sobrecarga de atividades domésticas e de cuidado, ${ }^{(10)}$ pouco suporte por parte da rede de apoio social e baixa renda, ${ }^{(11)}$ contudo não há, até o momento, evidências científicas de como a pandemia da COVID-19 repercutiu no cotidiano de mães-crianças com SCZ

Desse modo, esse estudo busca responder a seguinte questão: quais as repercussóes da pandemia da COVID-19 em mães-crianças com SCZ? A fim de alcançar o objetivo de analisar as repercussóes da pandemia da COVID-19 em mães-crianças com SCZ.

\section{Métodos}

Estudo misto sequencial exploratório (QUAL$>$ QUAN), ${ }^{(12)}$ apresentado conforme critérios do Mixed Methods Appraisal Tool (versão 2018) para avaliação do rigor metodológico de pesquisas mistas. ${ }^{(13)}$

As participantes foram recrutadas inicialmente nos grupos de WhatsApp da Associação de Pais de Anjos da Bahia (APAB), fundada em 2017, e da Associação aBRAÇO a Microcefalia (aBRAÇO) fundada em 2016, ambas com sede em Salvador, Bahia, Brasil. Destaca-se que os (as) pesquisadores (as) não integram os referidos grupos, tampouco entraram em contato com as participantes, visto que tal ação foi realizada por voluntários vinculadas as associaçóes. $\mathrm{O}$ contato inicial com as associaçóes foi realizado através do canal de teleatendimento oficial mediante conversa no aplicativo WhatsApp. 
Em seguida, utilizando a técnica Respondent Driven Sampling (RDS), ${ }^{(14)}$ as mães que primeiro participaram da pesquisa foram instadas a compartilhar o convite e instrumento de coleta de dados com outras mães, por esse motivo mães dos estados do Amazonas e Paraíba também responderam ao questionário da pesquisa. Essa técnica é recomendada para estudar grupos de pessoas de difícil acesso, ${ }^{(14)}$ o que se justifica pelo distanciamento físico vivido no Brasil durante a pandemia.

A coleta de dados ocorreu entre os meses de abril e maio de 2020. Participaram do estudo 44 mães de crianças com SCZ que respeitaram os seguintes critérios de inclusão: ser mãe de criança com SCZ e ter 18 anos de idade ou mais. Não houve critério de exclusão.

O número de participantes foi definido por saturação teórica-empírica ao se esgotar toda possibilidade de novas discussóes a partir dos dados coletados. $\mathrm{O}$ alcance da saturação ocorreu a medida que os núcleos de sentidos surgiam após o julgamento individual e confidencial de três pesquisadoras (es). Quando ocorreu convergência entre dois pesquisadores (as) foi encerrado o questionário online. A equipe em questão foi composta por duas pesquisadoras com qualificação de pós-doutorado e um doutorando.

Como técnica de coleta de dados utilizou-se questionário online, elaborado pelos (as) pesquisadores (as) através do Google Forms e compartilhado por meio do link <https://forms.gle/ Ztuu8x1gHgXeC38K6> nos grupos de WhatsApp. O questionário era composto por questōes fechadas relativas a caracterização socioeconômica das participantes e as atividades cotidianas realizadas antes e durante a pandemia, além das questóes abertas sobre as modificaçóes do dia-a-dia causadas pela pandemia. As respostas das participantes foram enviadas automaticamente para o e-mail sindromecongenitaz@gmail.com, administrado pelo primeiro autor.

A análise temática reflexiva foi realizada em seis etapas: leitura e releitura dos dados; criação de códigos para temas importantes (06 códigos); agrupamento dos códigos (02 grupos); construção de mapa mental identificando relações entre as temáticas; nomeação dos temas e; produção da síntese da análise. ${ }^{(15)}$
A análise qualitativa revelou a necessidade de comparar os níveis de sobrecarga da mãe antes e durante a pandemia. Para isso foi realizada a técnica de equivalência entre posiçóes das respostas qualitativas de acordo com a escala de sobrecarga do cuidador de Zarit, ${ }^{(16)}$ que mede o nível de sobrecarga do cuidador a partir de quatro domínios: "impacto na prestação de cuidado", destinado a tratar da percepçáo do cuidador sobre seus sentimentos, responsabilidades e cotidiano a partir do adoecimento; "relação interpessoal", que inclui questôes relacionadas a vida social do cuidador, dependência total da criança, autocuidado e despesas financeiras; "expectativas do cuidar", abrange a percepção da mãe sobre a qualidade do cuidado que ela realiza e; "percepção de autoeficácia”, constituído de duas questóes: você acha que poderia cuidar melhor da criança com SCZ? E, quanto você se sente sobrecarregada?

A escala de sobrecarga do cuidador é do tipo Likert, possui 22 itens direcionados ao bem-estar psicológico e socioeconômico do cuidador e sua relação com a pessoa a ser cuidada. Cada item possui cinco alternativas de resposta de acordo com a frequência que ocorrem: 0 (nunca); 1 (raramente); 2 (às vezes); 3 (frequentemente) e; 4 (sempre). Quanto maior a pontuação, maior a sobrecarga. ${ }^{(16)}$

$\mathrm{O}$ procedimento de equivalência entre posiçóes foi realizado entre a escala de sobrecarga do cuidador de Zarit e as respostas qualitativas coletadas a partir dos questionários online com pareamento em 18 itens da escala, seguindo as pontuaçóes disponíveis para cada item, conforme aporte metodológico evidenciado em estudo. ${ }^{(17)}$ A primeira etapa consistiu no agrupamento das respostas referentes ao cotidiano das mães-crianças antes e durante a pandemia, mantendo a individualidade das respostas. A segunda se configurou na organização das respostas de cada máe em temáticas afins dos domínios da escala de Zarit. Ao ler as respostas organizadas por domínio os autores relacionaram trechos delas com cada item daquele domínio, a fim de atribuir respostas para cada item. Feito isso, o próximo passo foi atribuir pontuação de cada resposta de acordo com a escala likert, conforme o sistema de pontuação apresentado no quadro 1 . 
Quadro 1. Classes equivalentes entre posições

\begin{tabular}{|l|l|}
\hline \multicolumn{2}{|c|}{ Equivalência entre as posições } \\
\hline Pontuação likert & Respostas qualitativas \\
\hline 4 (sempre) & $\begin{array}{l}\text { semântica do texto indica sobrecarga + presença de dois advérbios } \\
\text { de intensidade ou mais (p. ex. muito, bastante, demais, imenso) ou } \\
\text { duas palavras ou mais em negrito ou caixa alta }\end{array}$ \\
\hline 3 (frequentemente) & $\begin{array}{l}\text { semântica do texto indica sobrecarga + um advérbio de intensidade } \\
\text { (p. ex. muito, bastante, demais, imenso) e uma palavra em negrito } \\
\text { ou caixa alta }\end{array}$ \\
\hline 2 (ás vezes) & $\begin{array}{l}\text { semântica do texto indica sobrecarga + um advérbio de intensidade } \\
\text { (p. ex. muito, bastante, demais, imenso) ou uma palavra em negrito } \\
\text { ou caixa alta }\end{array}$ \\
\hline 1 (raramente) & semântica do texto indica sobrecarga \\
\hline 0 (nunca) & semântica do texto não indica sobrecarga \\
\hline
\end{tabular}

A estatística descritiva foi utilizada para caracterizar os aspectos sociodemográficos e econômicos da díade mãe-criança com a utilização de frequências absolutas e relativas. O teste $\mathrm{t}$ de Student pareado para amostras com distribuição normal foi utilizado para verificar a variação das médias dos domínios da sobrecarga do cuidador em variáveis numéricas. A significância estatística foi dada pelo valor de $\mathrm{p}<0,05$. A análise estatística foi processada pelo software Statistical Package for the Social Sciences (SPSS) versão 20.0. Para apresentar os dados QUAL e QUAN integrados foi utilizada a técnica joint display, uma única figura que dispóe os principais resultados QUAL e QUAN e as inferências elaboradas a partir da integração dos dados (meta-inferência). ${ }^{(18)} \mathrm{O}$ estudo foi aprovado pelo Conselho Nacional de Ética em Pesquisa. As participantes escolheram pseudônimos para manter o anonimato, respeitando as Resoluçóes no 466/12 e 510/16 do Conselho Nacional de Saúde do Brasil. O Termo de Consentimento Livre e Esclarecido (TCLE) estava disponível na primeira página do questionário online, aquelas que aceitaram participar da pesquisa indicaram entre contato por WhatsApp ou email como o melhor meio para receberem o TCLE assinado pelo pesquisador responsável e pesquisadora orientadora, sendo assim feito. Para aquelas que não aceitaram participar da pesquisa o questionário foi encerrado imediatamente.

O desenvolvimento do estudo atendeu as normas éticas nacionais de publicação e recebeu o número do parecer do comitê de ética 3.990.246 (CAAE 30757920.6.0000.0053).

\section{Resultados}

A tabela 1 apresenta as características sociodemográficas e econômicas das mães e crianças.

Tabela 1. Caracterização sociodemográficas e econômicas das mães-crianças com SCZ do Amazonas, Bahia e Paraíba $(n=44)$

\begin{tabular}{|c|c|}
\hline Variáveis & $n(\%)$ \\
\hline \multicolumn{2}{|l|}{ Idade da mãe } \\
\hline 18 a 20 & $1(2,3)$ \\
\hline 21 a 25 & $16(36,4)$ \\
\hline 26 a 30 & $5(11,4)$ \\
\hline 31 a 35 & $12(27,3)$ \\
\hline 36 a 40 & $7(15,9)$ \\
\hline 41 a 45 & $3(6,7)$ \\
\hline \multicolumn{2}{|l|}{ Idade da criança com SCZ } \\
\hline 0 a 1 ano 11 meses e 59 dias & $1(2,3)$ \\
\hline 2 anos a 3 anos 11 meses e 59 dias & $4(9,1)$ \\
\hline 4 anos a 5 anos completos & $39(88,6)$ \\
\hline \multicolumn{2}{|l|}{ Escolaridade } \\
\hline Nunca frequentei a escola mas sei ler e escrever & $1(2,3)$ \\
\hline Ensino fundamental incompleto & $3(6,8)$ \\
\hline Ensino fundamental completo & $3(6,8)$ \\
\hline Ensino médio incompleto & $8(18,2)$ \\
\hline Ensino médio completo & $23(52,3)$ \\
\hline Ensino superior incompleto & $3(6,8)$ \\
\hline Ensino superior completo & $2(4,5)$ \\
\hline Pós-graduação completa & $1(2,3)$ \\
\hline \multicolumn{2}{|l|}{ Religião } \\
\hline Católica & $15(34,1)$ \\
\hline Evangélica & $17(38,6)$ \\
\hline Não frequenta religião & $12(27,3)$ \\
\hline \multicolumn{2}{|l|}{ Cor da pele } \\
\hline Amarela & $1(2,3)$ \\
\hline Branca & $3(6,7)$ \\
\hline Parda & $20(45,5)$ \\
\hline Preta & $20(45,5)$ \\
\hline \multicolumn{2}{|l|}{ Ocupação } \\
\hline Autônoma & $2(4,7)$ \\
\hline Babá & $1(2,3)$ \\
\hline Costureira & $1(2,3)$ \\
\hline Desempregada & $4(9,3)$ \\
\hline Dona de casa & $26(58,3)$ \\
\hline Empregada doméstica & $1(2,3)$ \\
\hline Trabalhadoras de saúde & $5(11,6)$ \\
\hline Trabalhadoras de serviços administrativos & $3(6,9)$ \\
\hline Trabalhadoras de serviços industriais & $1(2,3)$ \\
\hline \multicolumn{2}{|l|}{ Renda familiar } \\
\hline Não revelado & $1(2,3)$ \\
\hline Sem renda & $3(6,8)$ \\
\hline Menor de $\mathrm{R} \$ 600,00$ & $1(2,3)$ \\
\hline Entre $R \$ 600,00$ e $R \$ 1.500,99$ & $34(77,3)$ \\
\hline Entre $\mathrm{R} \$ 1.501,00$ e $\mathrm{R} \$ 2.000,99$ & $3(6,8)$ \\
\hline Entre $\mathrm{R} \$ 2.001,00$ e $\mathrm{R} \$ 3.000,99$ & $2(4,5)$ \\
\hline \multicolumn{2}{|l|}{ Quantidade de moradores no mesmo domicílio } \\
\hline Dois & $12(27,3)$ \\
\hline Três & $12(27,3)$ \\
\hline Quatro & $12(27,3)$ \\
\hline Cinco & $5(11,3)$ \\
\hline Seis & $2(4,5)$ \\
\hline Sete & $1(2,3)$ \\
\hline \multicolumn{2}{|l|}{ Unidade Federativa do Brasil } \\
\hline Amazonas & $2(4,6)$ \\
\hline Bahia & $40(90,8)$ \\
\hline Paraíba & $2(4,6)$ \\
\hline
\end{tabular}


Em seguida, tem-se as categorias dos resultados: "Mudanças das atividades realizadas pela díade mãe-criança e seus efeitos" e "Repercussóes da pandemia da COVID-19 nos níveis de sobrecarga do cuidador em mães de crianças com SCZ”.

\section{Mudanças das atividades realizadas pela díade mãe-criança e seus efeitos}

A figura 1 ilustra o joint display que apresenta a modificação das atividades da mãe-criança e outras repercussôes como problemas no sono, abdicação de projetos pessoais e impossibilidade de compartilhamento do cuidado da criança com pessoas da rede de apoio.

\section{Repercussões da pandemia da COVID-19 nos níveis de sobrecarga do cuidador em mães de crianças com SCZ}

Os resultados QUAL e QUAN corroboram para elevação dos níveis de sobrecarga das mães durante a pandemia, observado pelo aumento dos valores médios em cada grupo (antes versus durante) e pelos depoimentos das mães apresentados no joint display a seguir (Quadro 2). Cabe destacar que em todos os pares de comparação verificou-se significância estatística $(\mathrm{p}<0,05)$, evidenciando que houve diferença na variação dos escores de sobrecarga do cuidador em mães intragrupos e intergrupos antes e durante a pandemia.

O escore global da sobrecarga do cuidador, representado pela soma dos quatro domínios, apresentou média maior durante a pandemia, com diferença entre as médias de 7,66 (antes $=44,38 \pm 10,47$ e durante $=52,04 \pm 9,12)\left(\mathrm{t}^{*} \quad(p \text {-value })^{\dagger}=-12,629\right.$ $(0,000))$, justificado por dificuldades financeiras e de acesso a alimentos; rompimento das relaçóes interpessoais; perda do controle sobre a situação de saúde da criança; desesperança; e realização dos cuidados de reabilitação e atividades escolares das crianças no ambiente doméstico, a fim de mitigar o retrocesso ou estagnação do desenvolvimento cognitivo e intelectual.

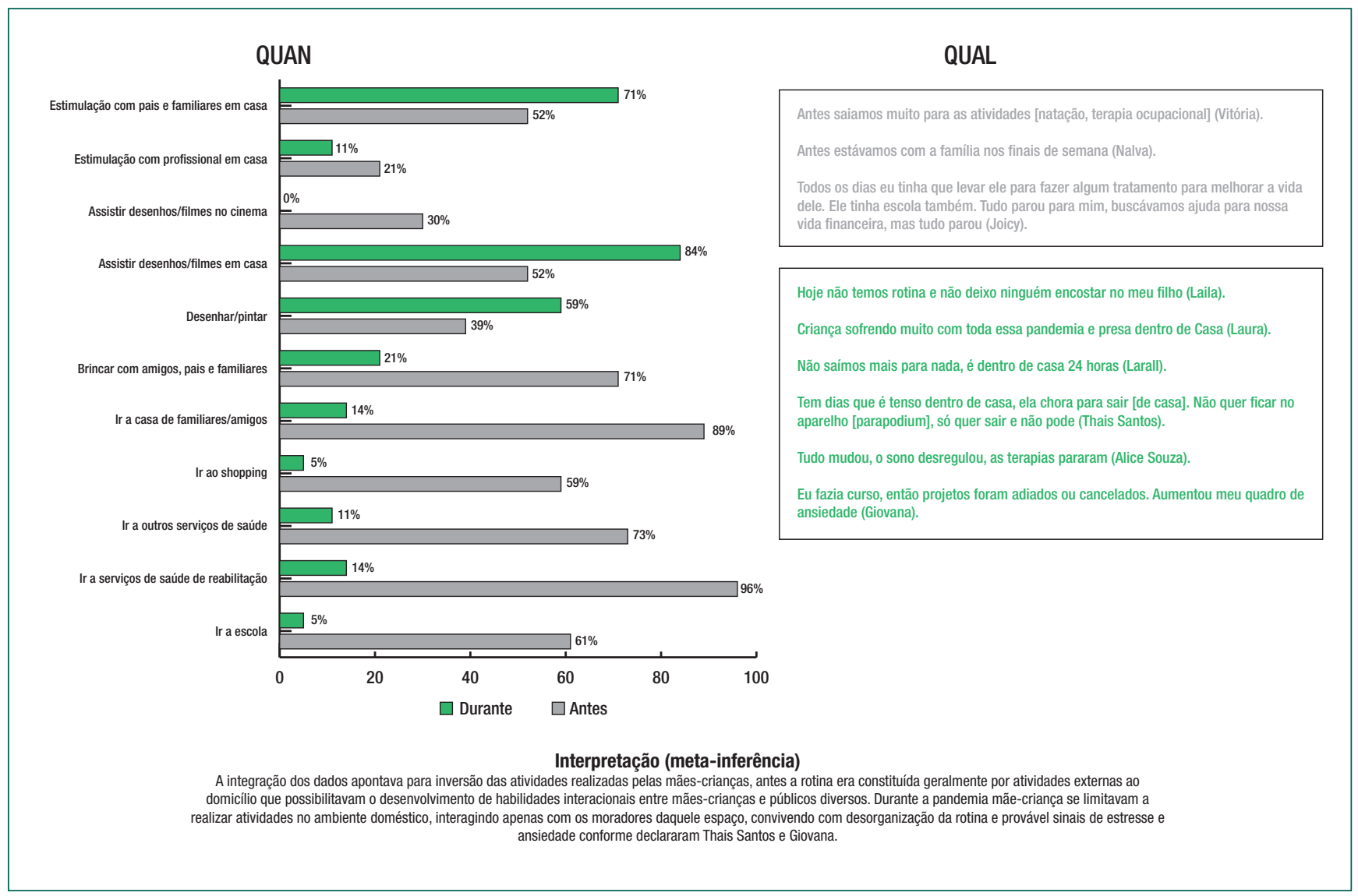

Figura 1. Atividades realizadas pelas mães-crianças antes e durante a pandemia da COVID-19 
Quadro 2. Domínios da escala de sobrecarga do cuidador, antes e durante a pandemia da COVID-19, em mães de crianças com SCZ do Amazonas, Bahia e Paraíba ( $\mathrm{n}=44)$

\begin{tabular}{|c|c|c|c|}
\hline \multirow{3}{*}{ Domínios da escala } & \multicolumn{3}{|c|}{ Sobrecarga do cuidador em mães de crianças com SCZ } \\
\hline & \multicolumn{2}{|l|}{ Resultados } & \multirow{2}{*}{\begin{tabular}{|l} 
Interpretação \\
(Meta-inferência)
\end{tabular}} \\
\hline & QUAN & QUAL & \\
\hline $\begin{array}{l}\text { Impacto na Prestação de } \\
\text { Cuidado }\end{array}$ & $\begin{array}{l}\text { Antes } \\
16,95 \pm 0,61 \\
\text { Durante } \\
18,00 \pm 0,65 \\
t^{*}(p-\text { valor })^{+} \\
-4,153(0,000)\end{array}$ & $\begin{array}{l}\text { Ficar dentro de casa direto com ele [criança com SCZ] dificulta muita coisa na minha vida (Glória). } \\
\text { As sessões de fisioterapia, fonoaudióloga e outros foram todas suspensas sem data de retorno. Então } \\
\text { eu mesma faço a reabilitação em casa, mesmo estando muito cansada. Tudo que aprendi nas sessões } \\
\text { faço com ele, eu me viro (Clara). } \\
\text { Fazer a estimulação em casa é difícil porque não temos os aparelhos de reabilitação (Larall). } \\
\text { A professora dele me ligou e colocou no WhatsApp e todo dia ela passa atividade para eu copiar e ele } \\
\text { fazer em casa e todo dia ele tá fazendo atividade. É muita coisa para mim (Maria José). } \\
\text { Tenho que limpar a casa mais de duas vezes no dia, tomamos banho várias vezes no dia (Edna). } \\
\text { Lavamos as mãos o tempo todo (Anall). }\end{array}$ & $\begin{array}{l}\text { Sugere-se que } 0 \text { impacto na prestação } \\
\text { de cuidado das mães se elevaram devido } \\
\text { a suspensão dos serviços de reabilitação } \\
\text { profissional e atividades escolares, } \\
\text { além da intensificação dos cuidados de } \\
\text { higiene pessoal e doméstica para evitar o } \\
\text { contágio da SARS-CoV-2. }\end{array}$ \\
\hline Relação Interpessoal & $\begin{array}{l}\text { Antes } \\
13,00 \pm 0,57 \\
\text { Durante } \\
16,36 \pm 0,49 \\
t^{\star}(p-\text { valor })^{\dagger} \\
-10,840(0,000)\end{array}$ & $\begin{array}{l}\text { Me afastei de todos, quando sair não posso ser contaminada, pois meus filhos precisam muito de mim } \\
\text { (Heloara). } \\
\text { Me preocupo em me contagiar e meu filho pegar essa maldita doença, porque ele não sabe falar } \\
\text { (Maria José). } \\
\text { Fico preocupada com a ausência de condições financeiras adequada para manter a família durante } \\
\text { esse período de surto (Heloisa). } \\
\text { Estou sem trabalhar (Laís). } \\
\text { Eu não gostei quando suspendeu a escola, porque também é mais um atraso. As crianças que estão } \\
\text { em casa têm direito a merenda na escola. Eles [governantes] deviam ajudar com cesta básica, porque } \\
\text { a prefeitura até agora não ajudou em nada (Maria José). }\end{array}$ & $\begin{array}{l}\text { As relações interpessoais das mães } \\
\text { foram possivelmente prejudicadas pelo } \\
\text { risco de contágio pessoal e contágio da } \\
\text { criança indiretamente. } \\
\text { As mães também convivem com } \\
\text { dificuldades financeiras e de acesso a } \\
\text { alimentos por conta do desemprego e } \\
\text { suspensão da oferta de merenda escolar. }\end{array}$ \\
\hline Expectativas do Cuidar & $\begin{array}{l}\text { Antes } \\
9,38 \pm 0,39 \\
\text { Durante } \\
12,25 \pm 0,38 \\
t^{*}(p-\text { valor })^{\dagger} \\
-9,999(0,000)\end{array}$ & $\begin{array}{l}\text { Tenho medo que morra as pessoas que mais amamos (Lara). } \\
\text { Medo de ver todo tratamento do meu filho se perder, depois de tantas conquistas (Joicy). } \\
\text { A falta de estimulação vai afetar a coordenação [motora da criança] (Patrícia). } \\
\text { Me preocupo com os atrasos porque tá sem o acompanhamento do profissional de reabilitação } \\
\text { (Vitória). }\end{array}$ & $\begin{array}{l}\text { Os depoimentos explicitam } \\
\text { posicionamentos de dúvida e perda do } \\
\text { controle das mães sobre a situação } \\
\text { de saúde da criança, resultando em } \\
\text { elevadas expectativas do cuidar. }\end{array}$ \\
\hline Percepção de Autoeficácia & $\begin{array}{l}\text { Antes } \\
5,04 \pm 0,25 \\
\\
\text { Durante } \\
5,43 \pm 0,23 \\
\\
\mathrm{t}^{\star}(\mathrm{p} \text {-valor })^{\dagger} \\
-2,864(0,006)\end{array}$ & $\begin{array}{l}\text { Então está tudo atrasado. A cirurgia que ele tinha para fazer foi desmarcada. Tudo na vida dele parou. } \\
\text { Será que vou conseguir recuperar o que meu filho perdeu no tratamento? (Joicy). } \\
\text { Cuido do meu filho } 24 \text { horas por dia, não tenho tempo pra mais nada (Isadora). } \\
\text { Me sinto sem esperança de oferecer um tratamento melhor para o meu filho (Alice Souza). }\end{array}$ & $\begin{array}{l}\text { Apesar do cuidado integral à criança, a } \\
\text { pandemia impôs condições que limitaram } \\
\text { os cuidados da mãe, dificultando o } \\
\text { desenvolvimento de atitudes cuidativas } \\
\text { eficazes contra os efeitos da suspensão } \\
\text { das terapêuticas e emergindo } \\
\text { sentimentos de desesperança. }\end{array}$ \\
\hline
\end{tabular}

*t: Teste t-Student para amostras pareadas; ${ }^{\dagger}: p$-value $<0,05$. Diferenças entre médias dos grupos antes e depois da pandemia.

\section{Discussão}

Por conta do distanciamento físico não foi possível utilizar outras técnicas de coleta de dados, condição que impossibilitou a condução da coleta de dados pelos pesquisadores, configurando-a como limitação do estudo.

Pela dependência total da criança com SCZ à mãe, é possível considerar a mãe como a pessoa com maior possibilidade de transmissão da COVID-19 à criança. Este aspecto justifica a prestação de serviço laboral remoto pela mãe e prioridade aos cuidados de prevenção para preservar a integridade da díade mãe-criança com SCZ em situaçóes pandêmicas.

Os resultados apontam para a implementaçáo de Planos de Cuidados de Enfermagem que diminuam a sobrecarga de cuidado materno, auxiliem na reorganização da rotina diária, estimulem o compartilhamento de tarefas entre familiares e rede de apoio social, beneficiem a qualidade do sono e fomentem açôes de sociabilidade da criança. Cabe sugerir que estudos científicos investiguem as atividades que sobrecarregam a mãe nesse período, assim como as prováveis consequências sobre desenvolvimento motor, intelectual e social da criança, resultantes da descontinuidade da assistência decorridas da pandemia.

O perfil socioeconômico das participantes confirma achados de estudos ${ }^{(15,19)}$ que evidenciaram a exposição do Zika vírus em grupos com maior vulnerabilidade, a exemplo da população negra e que vivem com baixos níveis de IDH. São pessoas que residem em áreas com condiçóes sanitárias precárias, nas quais se registra ausência de rede de água potável, escassez no abastecimento diário de água, sem cobertura de rede de esgoto, sem remoção regular de resíduos, dentre outras condiçóes que expóe mais as pessoas ao novo coronavírus. ${ }^{(9)}$ 
Com a COVID-19 a preocupação das mães reside, primeiramente, na possibilidade do contágio da criança, de si e outros moradores do domicílio, de modo que resulte no óbito do seu filho(a) ou restrinja seu cuidado com a criança que é totalmente dependente dela. ${ }^{(20)}$ Portanto, uma provável contaminação das mães por COVID-19 significa também o contágio direto da criança, a interrupção da reabilitação domiciliar, única terapêutica voltada ao desenvolvimento da criança que permanece durante a pandemia, ruptura das atitudes cuidativas como higienizar, nutrir, ninar e brincar, pois elas conhecem, praticam e coordenam esses cuidados cotidianamente, além da desestruturação de outros cuidados domésticos que também estão sob sua responsabilidade. ${ }^{(9)}$

Desse modo, pressupóe-se que a mãe deve ser considerada como a pessoa com maior possibilidade de transmitir a COVID-19 à criança, entendendo que o contágio dela culmina no contágio do (a) filho (a). Nessa condição, elas podem, por exemplo, serem priorizadas nos atendimentos dos serviços de saúde, além de negociar a flexibilidade da sua função e carga horária de trabalho com o empregador, conforme as recomendaçôes de distanciamento físico, diminuindo o risco de contágio da criança. Nesse estudo, supóe-se que $25,4 \%$ das máes realizam suas atividades laborais em ambiente extra doméstico, com necessidade de negociar o distanciamento físico com o empregador. Por outro lado, 67,6\% dedicam-se às tarefas domésticas e $7 \%$ podem trabalhar no domicílio, o que torna-se complexa e exaustiva a construção de uma rotina que englobe atividades laborais, educacionais, recreativas, domésticas, de sono e repouso, cuidado familiar e pessoal. ${ }^{(20)}$

Concomitante ao medo do óbito da criança, com a suspensão do tratamento de reabilitação, as mães acreditam na estagnação ou retrocesso do desenvolvimento da criança, mesmo realizando a reabilitação no ambiente doméstico conforme exercícios aprendidos junto aos profissionais de saúde. $^{(10)}$ As mães se esforçam para preencher a lacuna causada pela interrupção dos serviços de reabilitação, mesmo não conhecendo o nível de eficiência dos procedimentos de reabilitação realizados por familiares. Portanto, parece existir lacuna do conhecimento entre os níveis de eficiência da reabilitação profissional e doméstica, quando prováveis resultados poderiam ofertar confiança e segurança às mães para cuidar.

É frequente que profissionais de saúde demonstrem procedimentos aos cuidadores e os incentivem a realizarem estimulaçóes no domicílio. Contudo, essa única estimulação realizada pela mãe gera apreensão e insegurança quando dessas manobras de forma solo, devido ao pouco conhecimento e domínio para avaliar os estímulos e o desenvolvimento neuropsicomotor da criança.

As possibilidades de interação por meio remoto entre terapeutas, educadores e familiares podem auxiliar as mães em sua jornada domiciliar, bem como oferecer suporte para a realização das atividades escolares, já que 88,6\% das crianças desse estudo encontram-se em idade escolar. Contudo, infere-se que tal acompanhamento pode encontrar limites para ser executado pela mãe-criança devido ao acesso limitado a aparelhos eletrônicos e internet, visto que $88,7 \%$ delas apresentam renda familiar menor que $\mathrm{R} \$ 1.500,99$ reais e podem conviver com dificuldades para prover acesso virtual.

Além disso, recomenda-se que crianças mantenham contato com colegas da escola, educadores e amigos, seja por via virtual, ou envio de cartas, desenhos e pinturas, para manter a sociabilidade e o vínculo afetivo. ${ }^{(21)}$ Do contrário, o isolamento prolongado das crianças através da suspensão das atividades escolares e confinamento domiciliar podem resultar em prejuízos na saúde física e mental delas. ${ }^{(19)}$ Visto que a sociabilidade se configura como processo essencial para o desenvolvimento infantil, a pouca interação face a face pode repercutir em limitaçóes na formação da consciência, pois através das múltiplas interaçôes sociais as crianças se constituem sujeitos.

Mães de criança com SCZ, antes mesmo da pandemia, já conviviam com rotina exaustiva e sobrecarga do cuidado, ${ }^{(10)}$ resultando em elevados níveis de depressão, ${ }^{(19)}$ ansiedade, ${ }^{(22)}$ sofrimento mental, ${ }^{(20)}$ fadiga e níveis diminuídos de satisfação com a vida. ${ }^{(23)}$ Assim, a intensificação dos cuidados de higiene, a exigência da realização dos cuidados de reabilitação e a realização das atividades escolares 
desenvolvidas em domicílio, sem apoio da rede social, tende a intensificar o sofrimento físico e psicoemocional dessas mulheres durante a pandemia.

Essas repercussóes e adaptaçóes no cotidiano das mães são agravadas pelo volume dos noticiários sobre o número de casos e óbitos, circulação de notícias falsas, ${ }^{(24)}$ além da escassez de informaçóes sobre a COVID-19 e o cuidado da criança com deficiência, conjuntura que dificulta a escolha de condutas a serem assumidas pela mãe, ${ }^{(23)}$ deixando-a insegura. Do contrário, sabe-se que receber informaçóes precisas sobre as formas de transmissão e prevenção do contágio da COVID-19 está associada a menores níveis de ansiedade, depressão e estresse. ${ }^{(25,26)}$

Estudo indica que, durante a pandemia, as mulheres com problemas de saúde prévios pertencem ao grupo de pessoas com níveis significantes de ansiedade, depressão e estresse, resultando em sofrimento psíquico, ${ }^{(27)}$ portanto, acredita-se que as participantes deste estudo podem conviver com tais problemas de saúde. Ademais, elas perdem o modo de interação social face a face, ${ }^{(26)}$ veem sua renda familiar diminuir e a rotina ser ajustada. ${ }^{(27)}$ Outro estudo também aponta para a relação diretamente proporcional entre níveis de depressão e sobrecarga de cuidados em mães de crianças com déficit no desenvolvimento, além de relação inversamente proporcional com a qualidade do sono. ${ }^{(28)}$ Portanto, com o aumento da sobrecarga de cuidados durante a pandemia, as mães de crianças com SCZ podem sofrer com sintomas depressivos e má qualidade do sono.

A análise das médias dos domínios da escala de sobrecarga do cuidador evidenciou aumento durante a pandemia, apontando para a elevação da sobrecarga da mãe. Os itens do domínio "impacto na prestação de cuidado" indicam elevação da ansiedade, receio pelo futuro e restriçáo da privacidade das mães. O segundo domínio "relação interpessoal" sugere isolamento da mãe-criança devido às dificuldades para acionar pessoas que compóem sua rede de apoio social, além da redução da renda familiar. No terceiro domínio, o principal item que pode elevar as expectativas do cuidar é a perda do controle da própria vida pela cuidadora. No quarto domínio, denominado de "percepção da autoeficácia”, notou- -se que o aumento da sobrecarga pode estar associado ao medo do adoecimento pelo novo coronavírus. $\mathrm{O}$ aumento dessa percepção pode ser de natureza psicológica e culminar em desfechos negativos para a saúde mental, como ansiedade e depressão. ${ }^{(26)}$

Para mitigar as repercussóes do distanciamento físico, as mães necessitam se sentir seguras mediante demonstração de atenção, carinho e afeto dos familiares, possibilitada por contatos telefônicos ou videochamadas. ${ }^{(29)}$ Além disso, os profissionais podem contribuir ofertando orientaçôes terapêuticas de forma remota, a exemplo de técnicas de massoterapia e meditação, prover grupos de autoajuda online, estimular o autocuidado, solidariedade entre as pessoas, apresentar informaçóes atualizadas e confiáveis, e estratégias comprovadas no enfrentamento das repercussóes psicossociais em outros eventos epidêmicos. ${ }^{(30)}$

\section{Conclusão}

A pandemia da COVID-19 repercutiu no incremento de novas tarefas de cuidado com a criança e ambiente doméstico, bem como elevou os níveis de sobrecarga de cuidado das mães, o que pode resultar em alteraçóes importantes na saúde física e mental delas. Além disso, conviver com dificuldades financeiras, desorganização da rotina e má qualidade do sono pode culminar em desequilíbrio do processo saúde-doença.

\section{Colaborações}

Vale PRLF, Silva ES, Costa JSP, Carvalho RC e Carvalho ESS contribuíram com a concepção do estudo, análise e interpretação dos dados, redação do artigo, revisão crítica relevante do conteúdo intelectual e aprovação da versão final a ser publicada.

\section{Referências}

1. World Health Organization (WHO). Coronavirus Disease (COVID-19) Dashboard. Geneva: WHO; 2020 [cited 2021 Mar 7]. Available from: https://covid19.who.int/ 
2. Brasil. Ministério da Saúde. Painel de casos de doença pelo coronavírus 2019 no Brasil. Brasília (DF): Ministério da Saúde; 2020 [citado 2021 Mar 7]. Disponível em: https://covid.saude.gov.br/

3. Brasil. Ministério da Saúde. Boletim epidemiológico 02. Monitoramento dos casos de arboviroses urbanas transmitidas pelo Aedes (dengue, chikungunya e Zika), Semanas Epidemiológicas 01 a 52. Brasília (DF): Ministério da Saúde; 2020 [citado 2020 Mar 7]. Disponível em: https:// portalarquivos2.saude.gov.br/images/pdf/2020/janeiro/20/Boletimepidemiologico-SVS-02-1-.pdf

4. Oliveira AC, Lucas Coaglio T, Iquiapaza RA. What has the covid-19 pandemic taught us about adopting preventive measures?. Texto \& Contexto Enferm. 2020;29:e20200106.

5. Vale PR, Cerqueira S, Santos HP Jr, Black BP, Carvalho ES. Bad news: Families' experiences and feelings surrounding the diagnosis of Zikarelated microcephaly. Nurs Inq. 2019;26(1):e12274.

6. Teixeira GA, Dantas DN, Carvalho GA, Silva AN, Lira AL, Enders BC, et al. Analysis of the concept of the Zika Virus congenital syndrome. Ciênc Saúde Coletiva. 2020;25(2):567-74.

7. Tsang LP, Ng DC, Chan YH, Chen HY. Caring for the mother-child dyad as a family physician. Singap Med J. 2019;60(10):497-501.

8. Vale PR, Alves DV, Carvalho ES. "Very busy": daily reorganization of mothers to care of children with Congenital Zika Syndrome. Rev Gaúcha Enferm. 2020;41:e20190301.

9. Dos Santos Oliveira SJ, Dos Reis CL, Cipolotti R, Gurgel RQ, Santos VS, Martins-Filho PR. Anxiety, depression, and quality of life in mothers of newborns with microcephaly and presumed congenital Zika virus infection: a follow-up study during the first year after birth. Arch Womens Ment Health. 2017;20(3):473-5.

10. Vale PR, Alves DV, Amorim RC, Carvalho ES. Rosette of care for children with zika congenital syndrome: caring attitudes of relatives. Esc Anna Nery. 2020;24(3):e20190268.

11. Freitas PS, Soares GB, Mocelin HJ, Lacerda LC, Prado TN, Sales CM, et al. Síndrome congênita do vírus Zika: perfil sociodemográfico das mães. Rev Panam Salud Pública. 2018;19;43:1.

12. Creswell JW, Clark VP. Designing and conducting mixed methods research. 3rd ed. Califórnia: SAGE Publications; 2017.

13. Hong QN, Fàbregues $S$, Bartlett G, Boardman FK, Cargo M, Dagenais P, et al. The Mixed Methods Appraisal Tool (MMAT) version 2018 for information professionals and researchers. Education Information. 2018;34(10):1-7.

14. Nery GS, Souza SL, Melo LG, Santos Júnior EF. Aplicação do respondent driven sampling (rds) em adolescentes em situação de rua. Rev Lat Sociol. 2020;10(1):2253-6469.

15. Braun V, Clarke V. Reflecting on reflexive thematic analysis. Qual Res Sport Exerc Health. 2019;11(4):589-97.
16. Scazufca M. Brazilian version of the Burden Interview scale for the assessment of burden of care in carers of people with mental illnesses. Braz J Psychiatry. 2002;24(1):12-7.

17. Medeiros CA, Ribeiro AF, Galvão OF. Efeito de Instruções Sobre a Demonstração de Equivalência entre Posições. Psicol Teoria Pesquisa. 2003;19(2):165-71.

18. Guetterman TC, Fetters MD, Creswell JW. Integrating Quantitative and Qualitative Results in Health Science Mixed Methods Research Through Joint Displays. Ann Fam Med. 2015;13(6):554-61.

19. Kotzky K, Allen JE, Robinson LR, Satterfield-Nash A, Bertolli J, Smith $C$, et al. Depressive symptoms and care demands among primary caregivers of young children with evidence of congenital zika virus infection in Brazil. J Dev Behav Pediatr. 2019;40(5):344-53.

20. Freitas PS, Soares GB, Mocelin HJ, Lamonato LC, Sales CM, LindeArias AR, et al. How do mothers feel? Life with children with congenital Zika syndrome. Int J Gynaecol Obstet. 2020;148(Suppl 2):20-8.

21. Narzisi A. Handle the autism spectrum condition during coronavirus (COVID-19) stay at home period: ten tips for helping parents and caregivers of young children. Brain Sci. 2020;10(4):207.

22. Bulhões CS, Silva JB, Moraes MN, Reichert AP, Dias MD, Almeida AM. Psychic repercussions in mothers of children with congenital Zika virus syndrome. Esc Anna Nery. 2020;24(2):e20190230.

23. Souza LE, Lima TJ, Ribeiro EM, Pessoa AL, Figueiredo TC, Lima LB. Mental Health of Parents of Children with Congenital Zika Virus Syndrome in Brazil. J Child Family Studies. 2018;27:1207-15.

24. Barros-Delben P, Cruz RM, Trevisan KR, Gai MJ, Carvalho RV, Carlotto PA, et al. Saúde Mental em Situação de Emergência: COVID-19. Rev Debates Psychiatry. 2020;10(2)1-12.

25. Bao Y, Sun Y, Meng S, Shi J, Lu L. 2019-nCoV epidemic: address mental health care to empower society. Lancet. 2020;395(10224):e37-8.

26. Wang C, Pan R, Wan X, Tan Y, Xu L, Ho CS, et al. Immediate Psychological Responses and Associated Factors during the Initial Stage of the 2019 Coronavirus Disease (COVID-19) Epidemic among the General Population in China. Int J Environ Res Public Health. 2020;17(5):1729.

27. Cluver L, Lachman JM, Sherr L, Wessels I, Krug E, Rakotomalala S, et al. Parenting in a time of COVID-19. Lancet. 2020;395(10231):e64.

28. Lee J, Hayat MJ, Spratling R, SevcikRA, Clark PC. Relationship of Mothers' Mental and Physical Health to Characteristics of Mothers and Their Children With Developmental Disabilities. Nurs Res. 2018;67(6):456-64.

29. Kumar A, Nayar KR. COVID 19 and its mental health consequences [Editorial]. J Ment Health. 2020;27:1-2.

30. Chew QH, Wei KC, Vasoo S, Chua HC, Sim K. Narrative synthesis of psychological and coping responses towards emerging infectious disease outbreaks in the general population: practical considerations for the COVID-19 pandemic. Singapore Med J. 2020;61(7):350-6. 